\title{
Publisher Correction: GPCRmd uncovers the dynamics of the 3D-GPCRome
}

Ismael Rodríguez-Espigares (1), Mariona Torrens-Fontanals (D), Johanna K. S. Tiemann (1), David Aranda-García (D), Juan Manuel Ramírez-Anguita, Tomasz Maciej Stepniewski, Nathalie Worp, Alejandro Varela-Rial, Adrián Morales-Pastor, Brian Medel-Lacruz, Gáspár Pándy-Szekeres, Eduardo Mayol(D), Toni Giorgino (D),

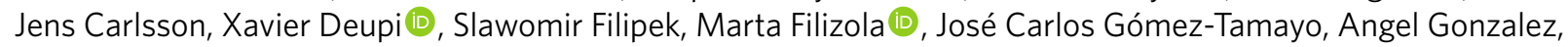

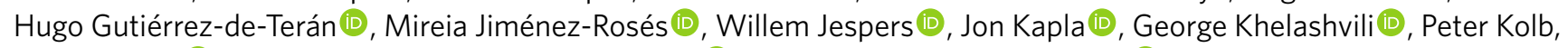
Dorota Latek (1), Maria Marti-Solano, Pierre Matricon (D), Minos-Timotheos Matsoukas (D, Przemyslaw Miszta, Mireia Olivella (1D, Laura Perez-Benito, Davide Provasi, Santiago Ríos BD, Iván R. Torrecillas, Jessica Sallander,

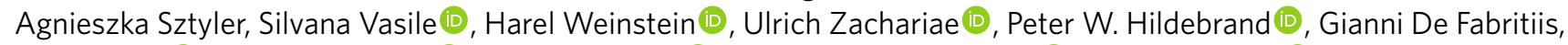

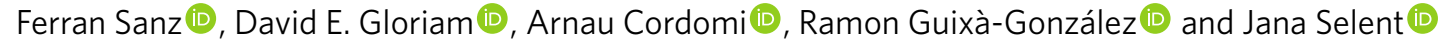

Correction to: Nature Methods https://doi.org/10.1038/s41592-020-0884-y, published online 13 July 2020.

In the version of this article initially published online, graphics elements were missing from Fig. 5b. The error has been corrected in the print, PDF and HTML versions of the article.

Corrected

b
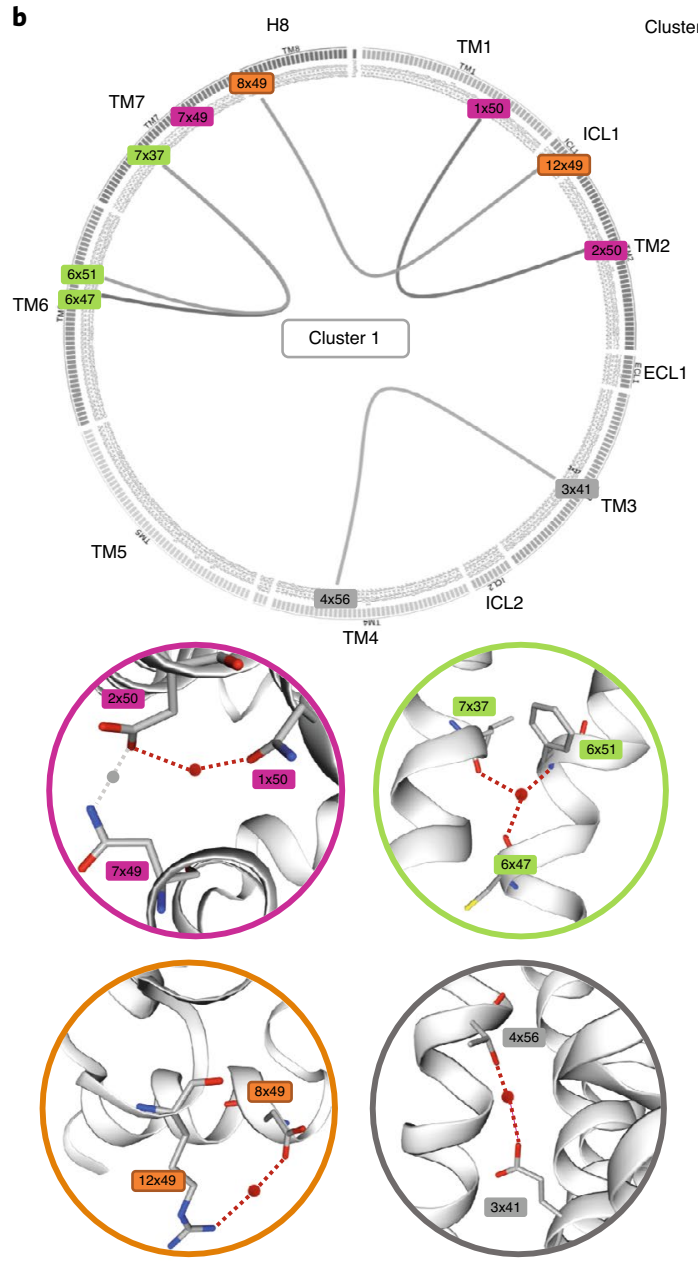

uster analysis
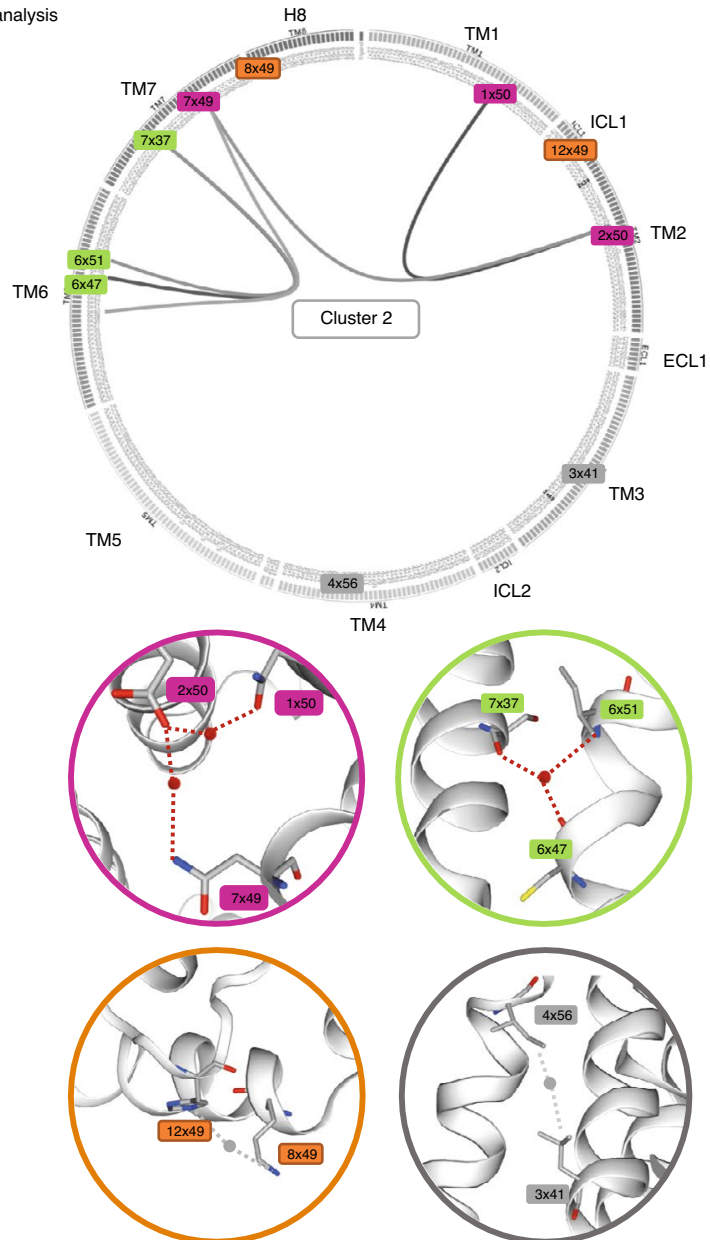

Fig. 5 | Corrected. 
Original

b
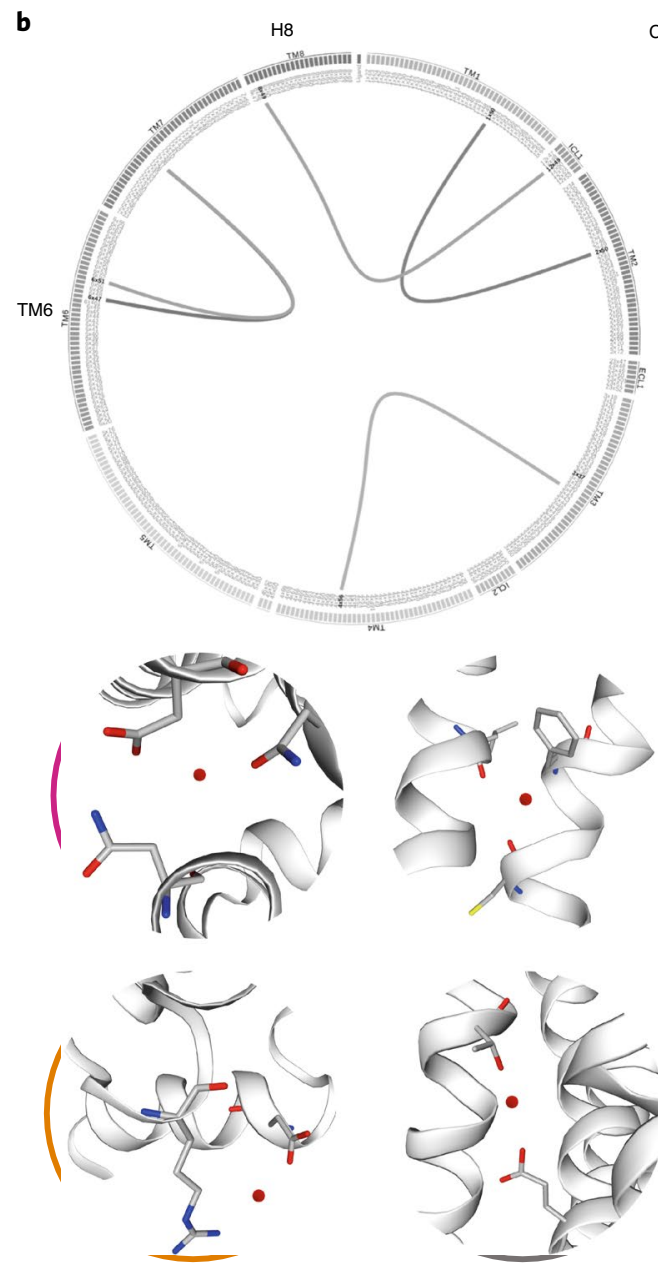

Cluster analysis
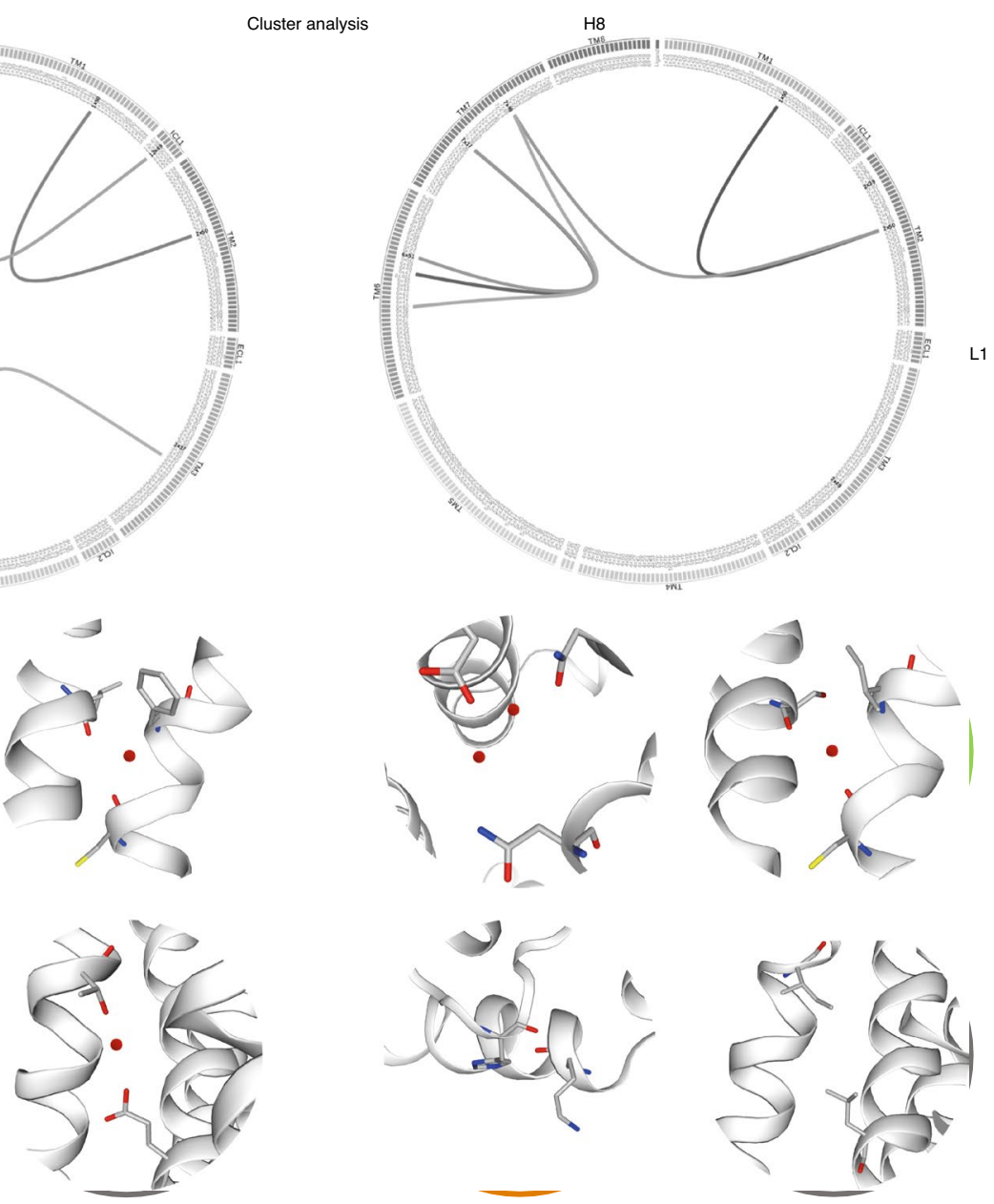
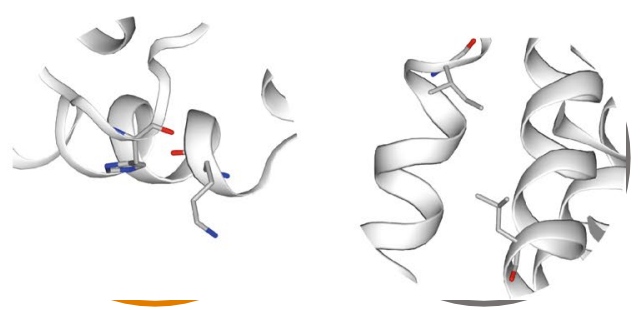

Fig. 5 | Original.

Published online: 23 July 2020

https://doi.org/10.1038/s41592-020-0928-3

(c) The Author(s), under exclusive licence to Springer Nature America, Inc. 2020 